\title{
Remission of Food Addiction Does Not Induce Cross-Addiction after Sleeve Gastrectomy and Gastric Bypass: A Prospective Cohort Study
}

\author{
Sonja Chiappetta ${ }^{a, b} \quad$ Christine Stier $^{b, c}$ Mohamed Ajan Hadid ${ }^{b}$ \\ Nina Malo ${ }^{b}$ Sophia Theodoridou $^{b}$ Rudolf Weiner $^{b}$ Sylvia Weinerd \\ a Department of Obesity and Metabolic Surgery, Ospedale Evangelico Betania, Naples, \\ Italy; ${ }^{b}$ Department of Obesity and Metabolic Surgery, Sana Klinikum Offenbach, \\ Offenbach am Main, Germany; ' Obesity Center NRW, Sana Kliniken Germany, Hürth, \\ Germany; ${ }^{d}$ Department of Obesity and Metabolic Surgery, Krankenhaus Nordwest, \\ Frankfurt am Main, Germany
}

\section{Keywords}

Addiction - Sleeve gastrectomy - Gastric bypass - Food addiction - Cross-addiction .

Addiction remission · Addiction transfer · Food · Alcohol · Nicotine · Exercise - Sport · Drug

\begin{abstract}
Background: The hypothesis of "cross-addiction" has never been validated, and numerous aspects speak against it. Objectives: To compare the differences between sleeve gastrectomy (SG) and gastric bypass (GB) procedures concerning cross-addiction. Setting: Center for maximum care in Germany. Methods: We performed a prospective analysis of patients undergoing SG or GB as the first surgical treatment for severe obesity. All patients completed validated questionnaires to evaluate food intake (Yale Food Addiction Scale, YFAS), alcohol intake (Alcohol Use Disorders Identification Test), nicotine use (Fagerstrom Test for Nicotine Dependence), exercise (Exercise Addiction Inventory), drug addiction (20-item Drug Abuse Screening Test), and Internet use disorder (Internet Addiction Test) before the operation (T0) and 6 (T6) and 24 (T24) months postoperatively (ClinicalTrials.gov identifier: NCT02757716). Results: One hundred thirteen patients underwent SG $(n=68)$ or GB $(n=45)$. At the follow-up, $61 \%$ completed the questionnaires at T6 and $44 \%$ at T24. In the YFAS, the percentage of patients diagnosed with food addiction decreased from 69 to $10 \%$, and the mean symptom count decreased from $3.52 \pm 1.95$ to $1.26 \pm 0.99$ at T24 ( $p<0.0001)$; these values did not differ between the surgical groups $(p=0.784)$. No significant evidence of cross-addiction was observed for
\end{abstract}

Work was performed at the Department of Obesity and Metabolic Surgery, Sana Klinikum Offenbach, Offenbach am Main, Germany. 
Chiappetta et al.: Addiction after Sleeve Gastrectomy and Gastric Bypass

use of alcohol, nicotine, drugs, the Internet, or exercise in either surgical group. The percentage of patients with moderate nicotine dependence increased in the SG group (+8.9\%) at T24, but this was not significant. Conclusion: In this single-center cohort study, surgery for obesity caused significant addiction remission regarding food but without inducing cross-addiction after 2 years. Importantly, no significant differences were seen between the SG and GB procedures.

(C) 2020 The Author(s)

Published by S. Karger AG, Basel

\section{Introduction}

Surgery for obesity and metabolic disorders can cause addiction remission regarding food and symptoms of addiction-like eating, as assessed using the Yale Food Addiction Scale (YFAS), and the risk of addiction remission has been shown to decrease following surgery [1, 2]. On the other hand, alcohol use disorders (AUDs) [3] and new-onset opioid use [4] are described as potential long-term complications after surgery that might be involved in crossaddiction over the long term. The hypothesis of "cross-addiction" or "addiction transfer" posits that patients who develop a de novo substance use disorder are those who had a preexisting "addiction" to food before surgery, which was "transferred" to another substance after surgery $[4,5]$. Evidence suggests that the rate of AUDs increases in a subset of patients after bariatric surgery [5] and that this phenomenon is more likely to occur after Roux-en-Y gastric bypass (RYGB) than after gastric banding [6]. The hypothesis of addiction transfer has never been validated, and recently several issues even speak against it. It seems that the risk of alcohol problems after bariatric surgery varies according to the type of procedure, which argues against the addiction transfer hypothesis. For example, Ivezaj et al. [7] noted that "if the impetus behind 'transferring' one's addictive behaviors from eating to a substance like alcohol is that surgery impedes an individual's ability to overeat, and/or because patients are purposefully changing their eating after surgery, then we would expect all metabolic bariatric surgeries to promote an equal risk for alcohol problems."

The microbiota-gut-brain axis plays a fundamental role in obesity and food addiction. Intestinal microorganisms convert dietary nutrients and induce the production of gut hormones, such as glucagon-like peptide 1, peptide YY, and cholecystokinin, which have different peripheral and central effects on the arcuate nucleus of the hypothalamus, where appetite and energy balance are regulated [8]. The gut hormones interact with the energy homeostatic system of the hypothalamus and convey information directly into the brain's reward pathways via vagal stimulation or indirectly through immune-endocrine mechanisms to affect the dopamine reward pathway in the ventral tegmental area, nucleus accumbens, and ventral pallidum [9]. In addition to food, opiates, alcohol, and nicotine also interact with dopamine and opioid neurons, and these interactions can interfere in the pathophysiology of addiction [10]. Obesity and metabolic surgery can change gut hormones, bile acids, and the gut microbiota, and the adaptations of gut physiology to surgery seem to differ between sleeve gastrectomy (SG) and gastric bypass (GB) [11].

Considering the importance of addiction remission regarding food and possible crossaddiction in the postoperative setting, the aim of this prospective study was to evaluate the prevalence of addiction (to food, alcohol, nicotine, exercise, and Internet use) in a group of patients before undergoing GB or SG and at 6 and 24 months after surgery, to compare the prevalence of cross-addiction between groups, and to identify possible predictors of the risk of cross-addiction.

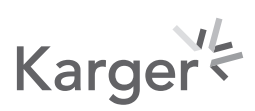


Chiappetta et al.: Addiction after Sleeve Gastrectomy and Gastric Bypass

\section{Materials and Methods}

We performed a prospective observational study using validated questionnaires to assess the changes in addiction after surgery for obesity and metabolic disorders at our institution. All patients who were admitted to receive their first surgical procedure, SG, RYGB, or one-anastomosis gastric bypass (OAGB), between April 2016 and November 2016 were recruited to participate. The eligibility criteria were a body mass index (BMI) $\geq 35$ and at least one metabolic disease or a BMI $\geq 40$, male or female adult patients, and a signed agreement to participate in the study.

Addiction was evaluated using validated questionnaires. All patients were given self-report questionnaires for investigating the following addictions or disorders: food addiction (YFAS); alcohol addiction (Alcohol Use Disorders Identification Test, AUDIT); nicotine addiction (Fagerstrom Test for Nicotine Dependence, FTND); exercise addiction (Exercise Addiction Inventory, EAI); Internet use disorder test (IAT); and drug addiction (Drug Abuse Screening Test, DAST-20). The questionnaires were completed 1 day before surgery (T0) and at 6 (T6) and 24 (T24) months of follow-up (FU). The patients' data were obtained from the medical report and included sex, age, height (cm), weight (kg), BMI (weight per height squared), Edmonton Obesity Staging System (EOSS) classification [12], and excess weight loss and total body weight loss (both expressed as a percentage).

All surgeries were performed at our institution, a high-volume certified center of excellence for obesity and metabolic surgery accredited by the European Accreditation Council for Bariatric Surgery. The surgical techniques for SG, RYGB, and OAGB have been described elsewhere [12]. The primary outcome measure was the change in addiction (addiction remission) regarding food. The secondary outcome measures were the changes in addiction regarding the use of alcohol, nicotine, the Internet, drugs, and exercise (to examine cross-addiction/addiction transfer) and weight loss, expressed as percent excessive weight loss and percent total weight loss.

Yale Food Addiction Scale 1.0

The YFAS is a 25-item instrument that measures symptoms of food addiction. It includes different scoring options (dichotomous and continuous scoring) to identify the experience of addictive eating behavior within the past 12 months. The range of food addiction symptoms is $0-7$. Food addiction is diagnosed as the presence of $\geq 3$ symptoms and a clinically significant impairment or distress (as assessed with two extra items) [13].

Alcohol Use Disorders Identification Test

The AUDIT is a 10-item instrument developed by the World Health Organization to assess alcohol use and alcohol-related consequences. A total score (range: $0-40$ ) is calculated using all 10 items, and a higher score reflects a greater severity of AUD. Participants were categorized as having AUD symptoms if their total AUDIT score was $\geq 8[14]$.

Fagerstrom Test for Nicotine Dependence

The FTND is a 6-item instrument to assess nicotine dependence that is graded on a 0-10 scale. A score of $\geq 5$ and $<8$ was used to define moderate nicotine dependence, and a cutoff $\geq 8$ was defined as strong nicotine dependence [15].

\section{Exercise Addiction Inventory}

The EAI is a 6-item instrument to assess exercise addiction and is graded on a 1-5 response scale with a total range of $6-30$. Higher scores indicate increased severity of symptoms. A score $\geq 13$ indicates a symptomatic individual, and a score $\geq 24$ indicates a person at risk of exercise addiction [16].

Internet Addiction Test

The IAT is a 20-item self-report scale that rates the degree of compulsive use, loss of control, negative consequences, and neglect in everyday life, and is rated on a 20-80 scale. Respondents with a score of 40-69 were classified as "addicted," and those with a score >69 were classified as "possibly addicted" [17].

Drug Abuse Screening Test

The DAST-20 is a 20-item instrument that measures drug abuse and is scored $0-20$. The phrase "drug abuse" includes any overtreatment involving medical drugs, such as pain killers, and nonmedical drug use, including illegal drugs. This includes substances such as marijuana, valium, cocaine, amphetamines, LSD, and heroin. A score $\geq 11$ indicates a high dependence [18].

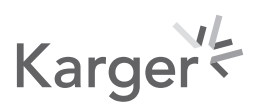


Obesity Facts

Table 1. Baseline demographic data: all patients $(n=113)$

\begin{tabular}{l|l}
\hline Obes Facts 2020;13:307-320 \\
\hline DOI: 10.1159/000506838 & $\begin{array}{l}\text { @ 2020 The Author(s). Published by S. Karger AG, Basel } \\
\text { www.karger.com/ofa }\end{array}$ \\
\hline
\end{tabular}

Chiappetta et al.: Addiction after Sleeve Gastrectomy and Gastric Bypass

\begin{tabular}{lccc}
\hline & Mean \pm SD & Minimum & Maximum \\
\hline Age, years & $44.2 \pm 9.9$ & 18 & 71 \\
Weight, kg & $146.5 \pm 31.2$ & 87 & 255.7 \\
BMI & & & \\
$\quad$ All $(n=113)$ & $51.7 \pm 9.8$ & 35 & 84.6 \\
SG $(n=68)$ & $51 \pm 8.6$ & 37.2 & 84.6 \\
RYGB $(n=22)$ & $44.2 \pm 4.5$ & 35 & 48.4 \\
OAGB $(n=23)$ & $59.8 \pm 10.3$ & 45.1 & 81.8 \\
TBWL, \% at 24 months FU & & & \\
All $(n=50)$ & $32 \pm 13.4$ & 5.69 & 58.7 \\
SG $(n=27)$ & $31.7 \pm 10.2$ & 13.4 & 48.3 \\
RYGB $(n=11)$ & $26.7 \pm 16.1$ & 5.69 & 50.3 \\
$\quad$ OAGB $(n=12)$ & $37.9 \pm 11.8$ & 13.6 & 58.5 \\
EBMIL, \% at 24 months FU & & & \\
All $(n=50)$ & $66.9 \pm 26.3$ & 11.3 & 124.4 \\
SG $(n=27)$ & $67 \pm 23.1$ & 26.8 & 124.4 \\
RYGB $(n=11)$ & $59.5 \pm 37.7$ & 11.3 & 116.8 \\
OAGB $(n=12)$ & $74.9 \pm 2$ & 49.7 & 107.2 \\
\hline
\end{tabular}

SD, standard deviation; BMI, body mass index; TBWL, total body weight loss; EBMIL, excess BMI loss; SG, sleeve gastrectomy, RYGB, Roux-en-Y gastric bypass; OAGB, one-anastomosis gastric bypass.

\section{Statistical Analysis}

Statistical analysis was performed using IBM SPSS Statistics for Windows (version 21.0; IBM Corp., Armonk, NY, USA). All variables were checked for a normal distribution. Continuous variables are expressed as mean \pm standard deviation (SD) and categorical data as percentages. Repeated-measures analysis of variance (ANOVA) and post hoc Bonferroni tests were used to identify significant differences from before to after the operation. For comparisons between the groups, a $2 \times 3$ mixed 2-factor repeated-measures ANOVA was used. The dependent variable was the change in scores in the different questionnaires, the withinsubjects factor was time (T0, T6, T24), and the between-subjects factor was surgical procedure (SG, GB). An interaction effect was calculated for each group. Intergroup differences were tested using a 2-sample $t$ test for normally distributed data, and between-group differences in categorical variables were evaluated using $\chi^{2}$ tests. A $p$ value $<0.05$ was considered to be significant.

The study was conducted in accordance with the principles of the Declaration of Helsinki. Ethical approval was obtained from the local ethics committee (Landesärztekammer Hessen, Germany, reference No. FF 146/2015), and all participants provided written informed consent for data sharing. The National Clinical Trials No. was NCT02757716 (https://clinicaltrials.gov/ct2/show/ NCT02757716).

\section{Results}

\section{Baseline Characteristics}

One hundred twenty patients were enrolled in this prospective study. A total of 113 patients fulfilled the study criteria. Seven patients were excluded because of a lack of consent or the surgical procedure was not performed. Before the operation, 113 patients completed the questionnaires evaluating food addiction (YFAS), alcohol addiction (AUDIT), nicotine addiction (FTND), exercise addiction (EAI), Internet addiction (IAT), and drug addiction (DAST-20). Sixty-nine (61\%) and 50 (44\%) patients completed questionnaires at T6 and T24, respectively. The baseline characteristics are listed in Table 1.

Seventy-seven (68\%) of the participants were women. Most patients were classified as EOSS grade 2 (73.6\%). Sixty-eight patients underwent SG (60\%) and 45 patients (40\%) underwent gastric bypass (RYGB $n=22$ or OAGB $n=23$ ) as the primary treatment for severe obesity. 


\begin{tabular}{l}
\begin{tabular}{l}
\hline Obes Facts 2020;13:307-320 \\
\hline DOI: 10.1159/000506838
\end{tabular} $\begin{array}{l}\text { (c) 2020 The Author(s). Published by S. Karger AG, Basel } \\
\text { www.karger.com/ofa }\end{array}$ \\
\hline
\end{tabular}

Table 2. Mean symptom scores and addiction cutoff of for the 6 questionnaires analyzing food addiction, alcohol addiction, nicotine addiction, exercise addiction, Internet addiction, and drug addiction in the whole study group (T0 $n=113$, T6 $n=69$, T24 $n=50$ ) and in the subgroups sleeve gastrectomy (SG) (T0 $n=68$, T6 $n=43$, T24 $n=27$ ) and gastric bypass (GB) (T0 $n=45$, T6 $n=27$, T24 $n=23$ )

\begin{tabular}{|c|c|c|c|c|c|}
\hline & $\begin{array}{l}\text { Proce- } \\
\text { dure }\end{array}$ & $\begin{array}{l}\text { T0 } \\
(n=113)\end{array}$ & $\begin{array}{l}\text { T6 } \\
(n=69)\end{array}$ & $\begin{array}{l}\text { T24 } \\
(n=50)\end{array}$ & $\begin{array}{l}p \text { time, } p \text { group, } \\
p \text { interaction timex } \\
\text { group }\end{array}$ \\
\hline Yale Food & All & $3.52 \pm 1.95(0-7)$ & $1.97 \pm 1.54(0-7)$ & $1.26 \pm 0.99(0-6)$ & $p$ time $<0.0001$ \\
\hline \multirow{2}{*}{ Addiction Scale } & SG & $3.51 \pm 1.9(1-7)$ & $2.21 \pm 1.64(0-7)$ & $1.11 \pm 0.75(0-3)$ & $p$ group $=0.784$ \\
\hline & GB & $3.53 \pm 2.03(0-7)$ & $1.59 \pm 1.31(0-5)$ & $1.43 \pm 1.2(0-6)$ & $\begin{array}{l}p \text { interaction timex } \\
\text { group }=0.326\end{array}$ \\
\hline \multirow[t]{3}{*}{ Food addiction score $\geq 3$} & All & $78(69 \%)$ & $21(30.4 \%)$ & $5(10 \%)$ & \\
\hline & SG & $46(67.6 \%)$ & $16(37.2 \%)$ & $2(7.4 \%)$ & \\
\hline & GB & $31(68.9 \%)$ & $5(18.5 \%)$ & $3(13 \%)$ & \\
\hline \multirow[t]{3}{*}{ AUDIT } & All & $1.81 \pm 1.8(0-13)$ & $1.74 \pm 2.72(0-14)$ & $1.08 \pm 2.01(0-11)$ & $p$ time $=0.067$ \\
\hline & SG & $1.93 \pm 2.39(0-13)$ & $2.4 \pm 3.22(0-14)$ & $0.96 \pm 1.4(0-4)$ & $p$ group $=0.288$ \\
\hline & GB & $1.64 \pm 2.04(0-8)$ & $0.7 \pm 1.07(0-4)$ & $1.22 \pm 2.58(0-11)$ & $\begin{array}{l}p \text { interaction time } \times \\
\text { group }=0.055\end{array}$ \\
\hline \multirow[t]{3}{*}{ Alcohol addiction score $\geq 8$} & All & $2(1.8 \%)$ & $4(5.8 \%)$ & $1(2 \%)$ & \\
\hline & SG & $1(1.5 \%)$ & $4(9.3 \%)$ & 0 & \\
\hline & GB & $1(2.2 \%)$ & 0 & $1(4.3 \%)$ & \\
\hline \multirow{3}{*}{$\begin{array}{l}\text { Fagerström Test for Nicotine } \\
\text { Dependence }\end{array}$} & All & $0.81 \pm 1.89(0-8)$ & $1.06 \pm 2.06(0-8)$ & $1.2 \pm 2.18(0-9)$ & $p$ time $=0.205$ \\
\hline & SG & $0.67 \pm 1.72(0-8)$ & $1 \pm 1.98(0-7)$ & $1.26 \pm 2.49(0-9)$ & $p$ group $=0.229$ \\
\hline & GB & $1.02 \pm 1.9(0-6)$ & $1.15 \pm 2.21(0-8)$ & $1.13 \pm 1.79(0-5)$ & $\begin{array}{l}p \text { interaction timex } \\
\text { group }=0.352\end{array}$ \\
\hline \multirow[t]{3}{*}{ Nicotine addiction score $\geq 5$} & All & $8(7.1 \%)$ & $7(10.1 \%)$ & $6(12 \%)$ & \\
\hline & SG & $4(5.9 \%)$ & $4(9.3 \%)$ & $4(14.8 \%)$ & \\
\hline & GB & $4(8.9 \%)$ & $3(11.1 \%)$ & $2(8.7 \%)$ & \\
\hline \multirow[t]{3}{*}{ Sport addiction test } & All & $9.65 \pm 2.19(9-18)$ & $10.3 \pm 2.73(9-27)$ & $9.98 \pm 1.78(9-15)$ & $p$ time $=0.175$ \\
\hline & SG & $9.97 \pm 1.93(9-18)$ & $10.4 \pm 3.14(9-27)$ & $10 \pm 2(9-15)$ & $p$ group $=0.994$ \\
\hline & GB & $9.62 \pm 1.37(9-16)$ & $10.15 \pm 1.96(9-18)$ & $9.96 \pm 1.58(9-14)$ & $\begin{array}{l}p \text { interaction timex } \\
\text { group }=0.459\end{array}$ \\
\hline \multirow[t]{3}{*}{ Sport addiction score $\geq 24$} & All & 0 & $1(1.4 \%)$ & 0 & \\
\hline & SG & 0 & $1(2.3 \%)$ & 0 & \\
\hline & GB & 0 & 0 & 0 & \\
\hline \multirow[t]{3}{*}{ IAT } & All & $25.89 \pm 8.43(20-73)$ & $24.57 \pm 7.44(20-51)$ & $24.26 \pm 7.96(20-60)$ & $p$ time $=0.545$ \\
\hline & SG & $26.07 \pm 7.94(20-56)$ & $24.79 \pm 7.8(20-51)$ & $23.22 \pm 5.83(20-46)$ & $p$ group $=0.396$ \\
\hline & GB & $25.62 \pm 9.22(20-73)$ & $24.22 \pm 6.96(20-44)$ & $25.48 \pm 9.91(20-60)$ & $\begin{array}{l}p \text { interaction time } \times \\
\text { group }=0.993\end{array}$ \\
\hline \multirow[t]{3}{*}{ Internet addiction score $\geq 69$} & All & $2(1.8 \%)$ & $1(1.4 \%)$ & $1(2 \%)$ & \\
\hline & SG & $1(1.5 \%)$ & $1(2.3 \%)$ & $0(3.7 \%)$ & \\
\hline & GB & $1(2.2 \%)$ & 0 & $1(4.3 \%)$ & \\
\hline \multirow[t]{3}{*}{ Drug use questionnaire } & All & $1.89 \pm 1.52(0-8)$ & $0.96 \pm 1.65(0-10)$ & $0.44 \pm 1.97(0-4)$ & $p$ time $=0.368$ \\
\hline & SG & $1.08 \pm 1.65(0-8)$ & $1.07 \pm 1.76(0-10)$ & $0.57 \pm 1.16(0-4)$ & $p$ group $=0.114$ \\
\hline & GB & $0.73 \pm 1.27(0-5)$ & $0.78 \pm 1.48(0-7)$ & $0.28 \pm 0.67(0-2)$ & $\begin{array}{l}p \text { interaction time } \times \\
\text { group }=0.913\end{array}$ \\
\hline Drug addiction score $\geq 11$ & All & 0 & 0 & 0 & \\
\hline
\end{tabular}

Table 2 summarizes the scores (with SD and range) and p values for all questionnaires and the prevalence of addiction based on the questionnaire cutoffs for the entire group and the SG and GB groups. Before surgery, $69 \%$ of the patients $(n=78)$ met the YFAS threshold for food addiction: 1.8\% $(n=2)$ for AUD, $7.1 \%(n=8)$ for nicotine use disorder, $0 \%$ for exercise addiction, $1.8 \%(n=2)$ for Internet use disorder, and $0 \%$ for drug abuse. 
Table 3. YFAS: endorsement rates for food addiction symptoms

\begin{tabular}{|c|c|c|c|c|}
\hline Food addiction symptoms & Question & $\begin{array}{l}\text { T0, } \\
\%\end{array}$ & $\begin{array}{l}\text { T6, } \\
\%\end{array}$ & $\begin{array}{l}\mathrm{T} 24 \\
\%\end{array}$ \\
\hline \multirow[t]{3}{*}{ Substance taken in larger amount and for longer period than intended } & 01 & 15.8 & 0 & 0 \\
\hline & 02 & 14.1 & 0 & 0 \\
\hline & 03 & 18.5 & 7.3 & 2 \\
\hline Persistent desire or repeated unsuccessful attempts to quit & 04 & 7.9 & 2.9 & 0 \\
\hline \multirow[t]{3}{*}{ Much time/activity to obtain, use, recover } & 05 & 28.2 & 5.8 & 2 \\
\hline & 06 & 13.2 & 0 & 0 \\
\hline & 07 & 18.5 & 1.5 & 2 \\
\hline \multirow{4}{*}{$\begin{array}{l}\text { Important social, occupational, or recreational activities given up or } \\
\text { reduced }\end{array}$} & 08 & 22.9 & 10.2 & 6 \\
\hline & 09 & 14.1 & 5.8 & 0 \\
\hline & 10 & 12.3 & 8.7 & 4 \\
\hline & 11 & 8.8 & 8.7 & 4 \\
\hline \multirow[t]{3}{*}{ Characteristic withdrawal symptoms } & 12 & 11.4 & 5.8 & 2 \\
\hline & 13 & 16.7 & 7.3 & 0 \\
\hline & 14 & 30.8 & 18.9 & 0 \\
\hline \multirow[t]{2}{*}{ Use causes clinically significant impairment or distress } & 15 & 42.2 & 11.6 & 4 \\
\hline & 16 & 28.1 & 8.7 & 0 \\
\hline \multirow[t]{3}{*}{ Use continues despite knowledge of adverse consequences } & 17 & 59 & 27.6 & 18 \\
\hline & 18 & 85.4 & 29 & 22 \\
\hline & 19 & 73.9 & 27.6 & 14 \\
\hline \multirow[t]{2}{*}{ Tolerance (marked increase in amount, decrease in effect) } & 20 & 36.1 & 26.1 & 6 \\
\hline & 21 & 35.2 & 23.2 & 12 \\
\hline \multirow[t]{4}{*}{ Persistent desire or repeated unsuccessful attempts to quit } & 22 & 82.7 & 75.4 & 60 \\
\hline & 23 & 84.5 & 75.4 & 66 \\
\hline & 24 & 54.6 & 40.6 & 42 \\
\hline & 25 & 52.8 & 45 & 28 \\
\hline
\end{tabular}

\section{Food Addiction (YFAS)}

The endorsement rates for specific food addiction symptoms are presented in Table 3 for the entire group and in Table 4 for the SG and GB groups. The two symptoms with the highest rates before and after surgery were the continued use despite knowledge of adverse consequences and the persistent desire or repeated unsuccessful attempts to quit. Figure 1 shows changes in mean symptom count at $\mathrm{T} 0, \mathrm{~T} 6$, and $\mathrm{T} 24$.

There was a significant main effect for time: Greenhouse-Geisser $F(1.49,46.27)=15.62$, $p<0.0001$, partial $\eta^{2}=0.335$. There was no significant main effect for group, which indicated that intervention groups did not differ significantly: $F(1,31)=0.077, p=0.784$, partial $\eta^{2}=$ 0.002 . There was no significant interaction between time and group: Greenhouse-Geisser $F(1.49,46.27)=1.1, p=0.326$, partial $\eta^{2}=0.034$.

No baseline differences regarding food addiction were seen in the YFAS for patients who dropped out of the study $(n=63)$ versus those who did not $(n=50)(p=0.648)$.

\section{Alcohol Addiction (AUDIT)}

Change in prevalence of alcohol addiction over time was higher in the SG group (+7.8\%) at T6, although this was not significant $(p=0.053)$. Two patients exhibited symptoms of alcohol addiction before surgery, and one still exhibited symptoms at T24. No de novo AUD was identified. Figure 2 shows the changes in mean symptom count at T0, T6, and T24. 
Chiappetta et al.: Addiction after Sleeve Gastrectomy and Gastric Bypass

Table 4. Endorsement rates for food addiction symptoms in the different surgical groups

\begin{tabular}{|c|c|c|c|c|c|c|c|c|}
\hline \multirow[t]{2}{*}{ Food addiction symptoms } & \multirow[t]{2}{*}{ Question } & \multicolumn{2}{|c|}{$\mathrm{T} 0, \%$} & \multicolumn{2}{|c|}{$\mathrm{T} 6, \%$} & \multicolumn{2}{|c|}{$\mathrm{T} 24, \%$} & \multirow{2}{*}{$\begin{array}{l}\Delta \mathrm{T} 0-\mathrm{T} 24 \\
\mathrm{~GB} \text { vs. SG }\end{array}$} \\
\hline & & GB & SG & GB & SG & GB & SG & \\
\hline \multirow{3}{*}{$\begin{array}{l}\text { Substance taken in larger amount and for longer } \\
\text { period than intended }\end{array}$} & 1 & 17.8 & 14.7 & 0 & 0 & 0 & 0 & 17.8 vs. 14.7 \\
\hline & 2 & 15.5 & 13.2 & 0 & 0 & 0 & 0 & 15.5 vs. 13.2 \\
\hline & 3 & 20 & 17.6 & 0 & 11.7 & 4.4 & 0 & 15.6 vs. 17.6 \\
\hline $\begin{array}{l}\text { Persistent desire or repeated unsuccessful } \\
\text { attempts to quit }\end{array}$ & 4 & 8.9 & 7.4 & 0 & 4.7 & 0 & 0 & 8.9 vs. 7.4 \\
\hline \multirow[t]{3}{*}{ Much time/activity to obtain, use, recover } & 5 & 28.9 & 27.9 & 7.4 & 4.7 & 4.4 & 0 & 24.5 vs. 27.9 \\
\hline & 6 & 13.3 & 13.2 & 0 & 0 & 0 & 0 & 13.3 vs. 13.2 \\
\hline & 7 & 20 & 17.6 & 0 & 2.3 & 4.4 & & 17.7 vs. 17.6 \\
\hline \multirow{4}{*}{$\begin{array}{l}\text { Important social, occupational, or recreational } \\
\text { activities given up or reduced }\end{array}$} & 8 & 26.6 & 20.6 & 3.7 & 14 & 13.1 & 0 & 13.5 vs. 20.6 \\
\hline & 9 & 17.8 & 11.8 & 0 & 9.3 & 0 & 0 & 17.8 vs. 11.8 \\
\hline & 10 & 4.4 & 17.6 & 7.4 & 9.3 & 8.7 & & -4.3 vs. 17.6 \\
\hline & 11 & 8.9 & 8.8 & 7.4 & 9.3 & 4.4 & 3.7 & 5.4 vs. 5.1 \\
\hline \multirow[t]{3}{*}{ Characteristic withdrawal symptoms } & 12 & 11.4 & 13.3 & & 9.3 & 0 & 3.7 & 11.4 vs. 9.6 \\
\hline & 13 & 16.7 & 22.2 & 3.7 & 9.3 & 0 & 0 & 16.7 vs. 22.2 \\
\hline & 14 & 30.8 & 37.7 & 3.7 & 28 & 0 & 0 & 30.8 vs. 37.7 \\
\hline \multirow{2}{*}{$\begin{array}{l}\text { Use causes clinically significant impairment or } \\
\text { distress }\end{array}$} & 15 & 40 & 44.1 & 3.7 & 16.3 & 0 & 7.4 & 40 vs. 36.7 \\
\hline & 16 & 24.4 & 30.9 & 0 & 14 & 0 & 0 & 24.4 vs. 30.9 \\
\hline \multirow{3}{*}{$\begin{array}{l}\text { Use continues despite knowledge of adverse } \\
\text { consequences }\end{array}$} & 17 & 46.6 & 67.6 & 11.1 & 37.3 & 13.1 & 22.2 & 33.5 vs. 45.4 \\
\hline & 18 & 82.1 & 88.2 & 18.5 & 35 & 17.4 & 22.2 & 64.7 vs. 66 \\
\hline & 19 & 71 & 76.4 & 25.9 & 28 & 17.4 & 11.1 & 53.6 vs. 65.3 \\
\hline \multirow{2}{*}{$\begin{array}{l}\text { Tolerance (marked increase in amount, decrease } \\
\text { in effect) }\end{array}$} & 20 & 31.1 & 39.7 & 11.1 & 35 & 4.4 & 7.4 & 26.7 vs. 32.3 \\
\hline & 21 & 40 & 32.3 & 18.5 & 25.6 & 8.7 & 14.8 & 31.3 vs. 17.5 \\
\hline \multirow{4}{*}{$\begin{array}{l}\text { Persistent desire or repeated unsuccessful } \\
\text { attempts to quit }\end{array}$} & 22 & 79.9 & 85.3 & 59.2 & 83.9 & 56.6 & 62.9 & 23.3 vs. 22.4 \\
\hline & 23 & 84.4 & 85.3 & 59.2 & 83.9 & 56.6 & 74 & 27.8 vs. 11.3 \\
\hline & 24 & 53.3 & 55.9 & 18.5 & 53.6 & 21.8 & 59.2 & 31.5 vs. -3.3 \\
\hline & 25 & 46.6 & 57.3 & 33.3 & 51.3 & 26.1 & 29.6 & 20.5 vs. 27.7 \\
\hline
\end{tabular}

SG, sleeve gastrectomy; GB, gastric bypass.

There was no significant main effect for time: Greenhouse-Geisser $F(1.93,59.86)=2.85$, $p=0.067$, partial $\eta^{2}=0.084$. There was no significant main effect for group, which indicated that intervention groups did not differ significantly: $F(1,31)=1.17, p=0.288$, partial $\eta^{2}=$ 0.036. There was no significant interaction between time and group: Greenhouse-Geisser $F(1.93,59.86)=3.085, p=0.055$, partial $\eta^{2}=0.091$.

Nicotine Addiction (FTND)

In the entire group, 26 patients (23\%) were smokers before surgery. Five of the patients had quit smoking at $\mathrm{T} 6$, but restarted after $\mathrm{T} 6$, and none of the smokers had stopped smoking by T24. At T24, 10 de novo smokers were identified, 6 of whom were in the SG group and 4 in the GB group. An increase in nicotine addiction (FTND score $\geq 5$ ) was seen in the SG group with a prevalence of $5.9 \%$ before surgery and $14.8 \%$ at T24 ( $p=0.218)$. Figure 3 shows the changes in mean symptom count at $\mathrm{T} 0, \mathrm{~T} 6$, and $\mathrm{T} 24$.

There was no significant main effect for time: Greenhouse-Geisser $F(1.59,49.25)=1.66$, $p=0.205$, partial $\eta^{2}=0.051$. There was no significant main effect for group, which indicated 


\section{Obesity Facts}

Fig. 1. Yale Food Addiction Scale mean symptom count: there was a significant main effect for time, $p<0.0001$, but intervention groups did not differ significantly, $p=$ 0.784 .

Fig. 2. Alcohol Use Disorders Identification Test - mean symptom count: there was no significant main effect for time, $p=$ 0.067, and intervention groups did not differ significantly, $p=$ 0.288 .

Fig. 3. Fagerstrom Test for Nicotine Dependence- mean symptom count: there was no significant main effect for time, $p=$ 0.205 , and intervention groups did not differ significantly, $p=$ 0.229 .
Chiappetta et al.: Addiction after Sleeve Gastrectomy and Gastric Bypass
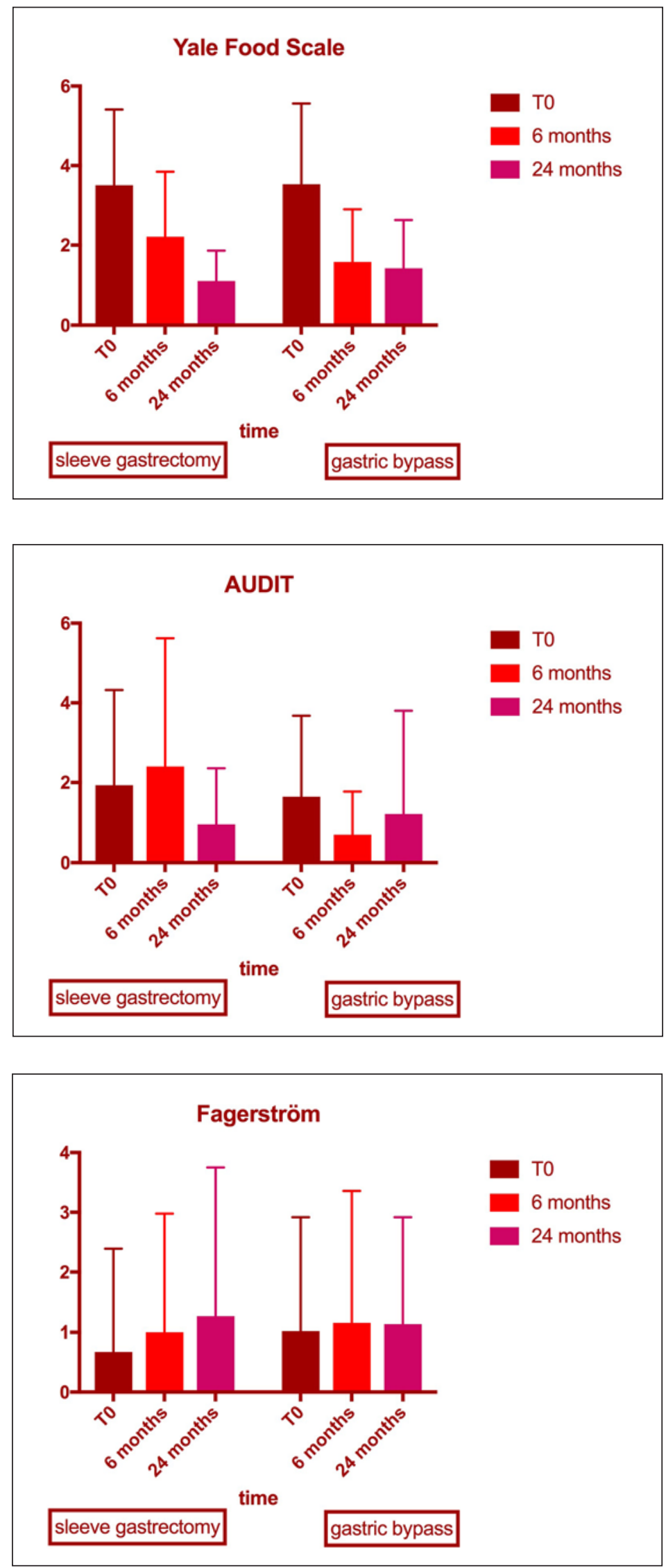
that the intervention groups did not differ significantly: $F(1,31)=1.51, p=0.229$, partial $\eta^{2}$ $=0.046$. There was no significant interaction between time and group: Greenhouse-Geisser $F(1.59,49.25)=1.023, p=0.352$, partial $\eta^{2}=0.032$.

\section{Exercise Addiction (EAI)}

There was no significant main effect of time: Greenhouse-Geisser $F(1.80,55.85)=1.82$, $p=0.175$, partial $\eta^{2}=0.055$. There was no significant main effect for group, which indicated that intervention groups did not differ significantly: $F(1,31)=0, p=0.994$, partial $\eta^{2}=0$. There was no significant interaction between time and group: Greenhouse-Geisser $F(1.80$, $55.85)=0.762, p=0.459$, partial $\eta^{2}=0.024$.

Internet Addiction (IAT)

There was no significant main effect of time: Greenhouse-Geisser $F(1.8,55.68)=0.58$, $p=0.545$, partial $\eta^{2}=0.018$. There was no significant main effect for group, which indicated that intervention groups did not differ significantly: $F(1,31)=0.74, p=0.396$, partial $\eta^{2}=$ 0.023 . There was no significant interaction between time and group: Greenhouse-Geisser $F(1.8,55.68)=0.004, p=0.993$, partial $\eta^{2}=0$.

\section{Drug Addiction (DAST-20)}

There was no significant main effect for time: Greenhouse-Geisser $F(1.9,44.13)=1.02$, $p=0.368$, partial $\eta^{2}=0.042$. There was no significant main effect for group, which indicated that intervention groups did not differ significantly: $F(1,23)=2.71, p=0.114$, partial $\eta^{2}=$ 0.105 . There was no significant interaction between time and group: Greenhouse-Geisser $F(1.9,44.13)=0.084, p=0.913$, partial $\eta^{2}=0.004$. No form of drug addiction was reported before or after the operation.

\section{Discussion}

Food addiction seems to correlate with obesity and disordered eating behaviors $[19,20]$, and there is evidence of a shared pathophysiological nature of food addiction and substance use disorders [9]. In this study, we analyzed addiction remission regarding food and possible addiction transfer involving the use of alcohol, nicotine, drugs, the Internet, and exercise in 113 patients undergoing surgery for obesity and metabolic disorders, whom we followed for 24 months. We focused on the differences in addiction remission and addiction transfer after SG and GB because changes in gut hormones, bile acids, and gut microbiota may affect the gut-brain axis and because the adaptation of gut physiology seems to differ between the two procedures [11].

\section{Food Addiction}

In our study cohort, $69 \%$ of patients had a diagnosis of food addiction before the operation, and this percentage decreased to $30.4 \%$ at $\mathrm{T} 6$ and to $10 \%$ at $\mathrm{T} 24$. This finding confirms the current belief that food addiction decreases significantly during the first postoperative year [21]. The prevalence of food addiction was higher at the baseline in our cohort compared with other surgical cohorts, whose rates of food addiction were reported in the range of 14-57.8\% [21]. The higher prevalence of food addiction in our study may be explained by the higher mean BMI of 51.7 and the often delayed step to surgery because of the German health insurance companies. In our cohort, we found no significant differences in addiction remission between GB and SG.

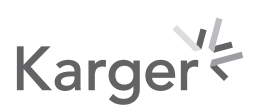


Chiappetta et al.: Addiction after Sleeve Gastrectomy and Gastric Bypass

Our analysis of the YFAS showed that the two most frequent symptoms reported before and after surgery were the continued use despite knowledge of adverse consequences and the persistent desire or repeated unsuccessful attempts to quit. The continued use despite knowledge of adverse consequences was identified by the answers to question 18, "My food consumption has caused significant physical problems or made a physical problem worse" and question 19, "I kept consuming the same types of food or the same amount of food even though I was having emotional and/or physical problems." The persistent desire or repeated unsuccessful attempts to quit were identified by the answers to question 22, "I want to cut down or stop eating certain kinds of food" and question 23, "I have tried to cut down or stop eating certain kinds of food." A recent Italian study confirmed the higher prevalence of the symptom "continued use despite knowledge of adverse consequences" and "the persistent desire or repeated unsuccessful attempts to quit" in the YFAS in candidates for surgery compared with a control group [22].

Interestingly, the only important difference between the GB and SG groups at T24 was identified by question 24, "I have been successful at cutting down or not eating these kinds of food." The complex interactions within the gut-brain-endocrine axis are postulated to play a role in reducing food intake [11], and our study showed a significant reduction in food addiction at T24 after both surgical procedures. The reason why GB patients were more successful at cutting down or not eating certain kinds of food remains to be clarified. Postgastrectomy syndrome, which includes early and late dumping syndrome after gastric bypass surgery, may explain the difference [23]. Further research is needed to clarify whether patients with food addiction might benefit more from GB procedures.

Severity and prevalence of food addiction decrease after surgery for obesity and metabolic disorders [24]. RYGB induces a negative nonlinear trend for total food cravings over time [25]. By contrast, other studies have found that food cravings seem to remain strong after RYGB [26] and loss-of-control eating is associated with poorer outcomes for weight loss after SG [27]. Improvements in several eating behaviors correlate with a remission of food addiction, and presurgical food addiction does not seem to be related to postsurgical weight outcomes during the first postoperative year [21]. Pepino et al. [24] examined whether food addiction remits after surgery and whether this correlates with eating behaviors and weight loss in 44 patients undergoing RYGB, SG, or gastric banding. Using the YFAS, they found rates of food addiction of $32 \%$ before and $2 \%$ after surgery, which led to a weight loss of about $20 \%$, and improvement in several eating behaviors associated with food addiction. Sevinçer et al. [1] determined the rate of food addiction and whether it was associated with weight loss after surgery. They reported that $57.8 \%$ of the 166 patients undergoing SG or OAGB had a diagnosis of food addiction and that this decreased to $7.2 \%$ at 6 months $(p<0.001)$ and $13.7 \%$ at 12 months $(p<0.001)$ after the operation. No relationship was found between the mean symptom count in the YFAS and excess body weight loss [1].

\section{Alcohol Addiction}

The interference of food, opiates, alcohol, and nicotine with dopamine and opioid neurons may explain the pathophysiology of addiction transfer after surgery for obesity and metabolic disorders [10]. In addition, alcohol and nicotine consumption are associated with social grade and educational attainment $[28,29]$, and central obesity is more common among lower than higher socioeconomic status groups [30]. These findings suggest that patients should be screened for possible substance use disorder before surgery and for possible addiction transfer after surgery for obesity and metabolic disorders.

We found a higher prevalence of alcohol addiction at T6 in the SG group (+7.8\%) and a significantly higher mean symptom count in the SG group than in the GB group. However, both of these prevalence rates declined by T24 and did not differ significantly from those in

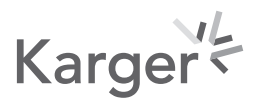


the presurgical assessment. The entire group (SG and GB groups combined) showed a significantly lower mean symptom score $(p=0.023)$ in the AUDIT score at T24. These results contrast with those of a prospective longitudinal study by King et al. [3], who found a significantly higher prevalence of AUD in the second postoperative year in men, younger participants, and in those who smoked or regularly consumed alcohol or recreational drugs, had a lower sense of belonging, or underwent RYGB. The adjusted odds ratio was 2.07 ( $95 \%$ confidence interval, 1.40-3.08; $p<0.001$; reference category, laparoscopic adjustable gastric band procedure). These variables were independently related to an increased risk of AUD after surgery for obesity and metabolic disorders [3].

The critical question about alcohol consumption noted by King et al. was whether the increase in alcohol consumption reflects the adjustment for caloric intake and/or a greater alcohol reward because of the reduced reward from previously highly preferred rich food items. Some evidence suggests that the risk for onset of AUD continues to increase rather than decrease over many years following surgery [3]. Ivezaj et al. [7] proposed that "if patients were experiencing a need to replace food and eating with some other type of substance or behavior, we would expect this need to be most acute within the early months after surgery, when patients are most limited in their intake capacity and their tolerance for highly palatable foods." We found a higher mean symptom count in the AUDIT at T6 and that, by T24, this count had decreased and did not differ significantly from that in the presurgical assessment. Because our study showed no addiction transfer at $\mathrm{T} 24$, it was not possible to identify possible predictive factors in our study cohort.

\section{Nicotine Addiction}

Rates of overweight and obesity are higher among more dependent smokers [31], but only a few studies have investigated the prevalence of food addiction and substance-related addictive disorders such as nicotine addiction. Müller et al. [32] found a prevalence of $6 \%$ for nicotine use disorder in 216 patients undergoing surgery for obesity and metabolic disorders. In our study cohort, we found an elevated rate of nicotine addiction at T24, especially after SG, as shown by a prevalence of $+8.9 \%$ and a higher mean symptom count over time ( $0.67 \mathrm{vs}$. 1.26), although these differences were not significant. Our postoperative recommendations might explain the higher nicotine abuse score after SG in correlation with that after GB. Patients are recommended to stop smoking after GB surgery to avoid the increased risk of anastomotic ulceration [33]. On the other hand, none of the smokers had stopped smoking at T24. Changes in gut hormones after GB surgery [34] may also interfere with the brain rewards pathway and diminish the rate of addiction transfer to nicotine.

The results of our study regarding nicotine addiction provide new information and are important for clinical practice. One new point is that, despite the recommendation to stop smoking, those who smoked had not ceased smoking at T24. Second, 10 de novo smokers were identified at T24, 6 of whom were in the SG group and 4 in the GB group. The higher rate of nicotine addiction may be related to a possible addiction transfer to satisfy the dopamine reward pathway.

\section{Exercise, Internet and Drug Addiction}

Interestingly, no addiction transfer involving sport and Internet addiction was seen in either surgical group. Li et al. [35] evaluated the relationship between obesity and Internet addiction, and found that obesity was not a predictor of Internet addiction. By contrast, Müller et al. [32] found a weak association between obesity with Internet use disorder in 216 patients. Addiction has not been studied yet. We found no evidence of addiction transfer involving Internet and exercise after surgery. The DAST-20 drug use questionnaire showed no significant change in the mean symptom count over time and no interaction between time and

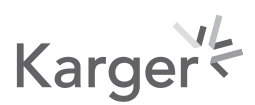


Chiappetta et al.: Addiction after Sleeve Gastrectomy and Gastric Bypass

group. In addition, no drug addiction was seen in the entire group either before or after the operation.

In our hospital, education about nutritional behavior, and supplementation with proteins, vitamins, and minerals before surgery and continuously during the FU is mandatory. Malnutrition can lead to symptoms of depression, anxiety, and low energy, which can lead some people to start using drugs or alcohol, or trigger a relapse [36].

\section{Limitations}

The present study has some limitations that should be considered when interpreting the findings. First, the prevalence estimates for all addictive disorders were based predominantly on questionnaire thresholds, and this might interfere with the diagnosis. On the other hand, questionnaires were used to identify patients at risk and every patient was seen personally by a physician during the FU. Second, only $61 \%$ of patients completed the questionnaires at T6 and $44 \%$ at T24. Even though a study nurse distributed the questionnaires during the FU, the FU completion rates were low. This is a general problem in Germany and may be related to the high patient numbers in our high-volume center. Third, the prevalence of cross-addiction after surgery for obesity might have been too low to be detected in this small single-cohort study.

In conclusion, our single-center prospective cohort study showed that surgery for obesity causes significant addiction remission regarding food in both surgical groups without inducing significant cross-addiction at 2 years. We found no significant differences after the operation between the SG and GB procedures. The mean symptom count in the AUDIT score for alcohol addiction decreased significantly after both procedures, but a slightly higher prevalence of moderate nicotine dependence was observed especially after SG. Further studies are needed to identify possible predictors of the risk of addiction transfer after surgery for obesity.

\section{Acknowledgments}

The authors would like to acknowledge and thank Aurelia Szymanski, study nurse, for her support during the study time, and Alfonso Canfora and Alfonso Bosco (Ospedale Evangelico Betania, Naples, Italy) for the careful revision of the manuscript.

\section{Statement of Ethics}

Informed consent was obtained from all the individual participants included in the study. All procedures performed in this study involving human participants were in accordance with the ethical standards of the institutional and/or national research committee and with the 1964 Helsinki Declaration and its later amendments or comparable ethical standards.

\section{Disclosure Statement}

All authors have no conflicts of interest or financial ties to disclose.

\section{Author Contributions}

All authors performed substantial contributions to the conception and design of the article and to acquisition, analysis and interpretation of data. All authors reviewed the manuscript for important intellectual content and approved the final version for publication. All authors agree to be accountable for all aspects of the work in ensuring that questions related to the accuracy or integrity of any part of the work are appropriately investigated and resolved.

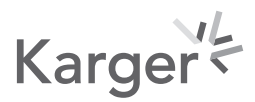




\begin{tabular}{l|l}
\hline Obes Facts 2020;13:307-320 \\
\hline DOI: 10.1159/000506838 & $\begin{array}{l}\text { (c) 2020 The Author(s). Published by S. Karger AG, Basel } \\
\text { www.karger.com/ofa }\end{array}$ \\
\hline
\end{tabular}

\section{References}

1 Sevinçer GM, Konuk N, Bozkurt S, Coşkun H. Food addiction and the outcome of bariatric surgery at 1 year: prospective observational study. Psychiatry Res. 2016 Oct;244:159-64.

2 Murray SM, Tweardy S, Geliebter A, Avena NM. A Longitudinal Preliminary Study of Addiction-Like Responses to Food and Alcohol Consumption Among Individuals Undergoing Weight Loss Surgery. Obes Surg. 2019 Aug; 29(8):2700-3.

3 King WC, Chen JY, Mitchell JE, Kalarchian MA, Steffen KJ, Engel SG, et al. Prevalence of alcohol use disorders before and after bariatric surgery. JAMA. 2012 Jun;307(23):2516-25.

4 Jakobsen GS, Småstuen MC, Sandbu R, Nordstrand N, Hofsø D, Lindberg M, et al. Association of Bariatric Surgery vs Medical Obesity Treatment With Long-term Medical Complications and Obesity-Related Comorbidities. JAMA. 2018 Jan;319(3):291-301.

5 Testino G, Fagoonee S. Alcohol Use Disorders and Bariatric Surgery. Obes Surg. 2018 Oct;28(10):3304-5.

6 King WC, Chen JY, Courcoulas AP, Dakin GF, Engel SG, Flum DR, et al. Alcohol and other substance use after bariatric surgery: prospective evidence from a U.S. multicenter cohort study. Surg Obes Relat Dis. 2017 Aug; 13(8):1392-402.

7 Ivezaj V, Benoit SC, Davis J, Engel S, Lloret-Linares C, Mitchell JE, et al. Changes in Alcohol Use after Metabolic and Bariatric Surgery: predictors and Mechanisms. Curr Psychiatry Rep. 2019 Aug;21(9):85.

8 Torres-Fuentes C, Schellekens H, Dinan TG, Cryan JF. The microbiota-gut-brain axis in obesity. Lancet Gastroenterol Hepatol. 2017 Oct;2(10):747-56.

9 Volkow ND, Wang GJ, Tomasi D, Baler RD. The addictive dimensionality of obesity. Biol Psychiatry. 2013 May; 73(9):811-8.

10 Nestler EJ. Is there a common molecular pathway for addiction? Nat Neurosci. 2005 Nov;8(11):1445-9.

11 Sinclair P, Brennan DJ, le Roux CW. Gut adaptation after metabolic surgery and its influences on the brain, liver and cancer. Nat Rev Gastroenterol Hepatol. 2018 Oct;15(10):606-24.

12 Chiappetta S, Stier C, Squillante S, Theodoridou S, Weiner RA. The importance of the Edmonton Obesity Staging System in predicting postoperative outcome and 30-day mortality after metabolic surgery. Surg Obes Relat Dis. 2016 Dec;12(10):1847-55.

13 Meule A, Heckel D, Kübler A. Factor structure and item analysis of the Yale Food Addiction Scale in obese candidates for bariatric surgery. Eur Eat Disord Rev. 2012 Sep;20(5):419-22.

14 Saunders JB, Aasland OG, Babor TF, de la Fuente JR, Grant M. Development of the Alcohol Use Disorders Identification Test (AUDIT): WHO Collaborative Project on Early Detection of Persons with Harmful Alcohol Consumption-II. Addiction. 1993 Jun;88(6):791-804.

15 Ríos-Bedoya CF, Snedecor SM, Pomerleau CS, Pomerleau OF. Association of withdrawal features with nicotine dependence as measured by the Fagerström Test for Nicotine Dependence (FTND). Addict Behav. 2008 Aug; 33(8):1086-9.

16 Griffiths MD, Szabo A, Terry A. The exercise addiction inventory: a quick and easy screening tool for health practitioners. Br J Sports Med. 2005 Jun;39(6):e30.

17 Jelenchick LA, Becker T, Moreno MA. Assessing the psychometric properties of the Internet Addiction Test (IAT) in US college students. Psychiatry Res. 2012 Apr;196(2-3):296-301.

18 Shimane T, Imamura A, Ikeda K, Yamamoto M, Tsuji M, Nagayo Y, et al. [Reliability and validity of the Japanese version of the DAST-20]. Nihon Arukoru Yakubutsu Igakkai Zasshi. 2015 Dec;50(6):310-24.

19 Şengör G, Gezer C. Food addiction and its relationship with disordered eating behaviours and obesity. Eat Weight Disord. 2019 Dec;24(6):1031-9.

20 Chao AM, Shaw JA, Pearl RL, Alamuddin N, Hopkins CM, Bakizada ZM, et al. Prevalence and psychosocial correlates of food addiction in persons with obesity seeking weight reduction. Compr Psychiatry. 2017 Feb;73: 97-104.

21 Ivezaj V, Wiedemann AA, Grilo CM. Food addiction and bariatric surgery: a systematic review of the literature. Obes Rev. 2017 Dec;18(12):1386-97.

22 Bianciardi E, Fabbricatore M, Di Lorenzo G, Innamorati M, Tomassini L, Gentileschi P, et al. Prevalence of Food Addiction and Binge Eating in an Italian sample of bariatric surgery candidates and overweight/obese patients seeking low-energy-diet therapy. Riv Psichiatr. 2019 May-Jun;54(3):127-30.

23 Emous M, Wolffenbuttel BH, van Dijk G, Totté E, van Beek AP. Long-term self-reported symptom prevalence of early and late dumping in a patient population after sleeve gastrectomy, primary, and revisional gastric bypass surgery. Surg Obes Relat Dis. 2018 Aug;14(8):1173-81.

24 Pepino MY, Stein RI, Eagon JC, Klein S. Bariatric surgery-induced weight loss causes remission of food addiction in extreme obesity. Obesity (Silver Spring). 2014 Aug;22(8):1792-8.

25 Cushing CC, Peugh JL, Brode CS, Inge TH, Benoit SC, Zeller MH. Longitudinal trends in food cravings following Roux-en-Y gastric bypass in an adolescent sample. Surg Obes Relat Dis. 2015 Jan-Feb;11(1):14-8.

26 Sudan R, Sudan R, Lyden E, Thompson JS. Food cravings and food consumption after Roux-en-Y gastric bypass versus cholecystectomy. Surg Obes Relat Dis. 2017 Feb;13(2):220-6.

27 Ivezaj V, Kessler EE, Lydecker JA, Barnes RD, White MA, Grilo CM. Loss-of-control eating following sleeve gastrectomy surgery. Surg Obes Relat Dis. 2017 Mar;13(3):392-8.

28 Beard E, Brown J, West R, Kaner E, Meier P, Michie S. Associations between socio-economic factors and alcohol consumption: a population survey of adults in England. PLoS One. 2019 Feb;14(2):e0209442. 
29 Brath H, Kaser S, Tatschl C, Fasching P. [Smoking, alcohol and diabetes (Update 2019)]. Wien Klin Wochenschr. 2019 May;131(S1 Suppl 1):67-70.

30 Steptoe A, Hiltl TJ, Dowd JB, Hamer M. Socioeconomic status and central adiposity as determinants of stressrelated biological responses relevant to cardiovascular disease risk. Brain Behav Immun. 2019 Mar;77:16-24.

31 Strong DR, David SP, Johnstone EC, Aveyard P, Murphy MF, Munafò MR. Differential Efficacy of Nicotine Replacement Among Overweight and Obese Women Smokers. Nicotine Tob Res. 2015 Jul;17(7):855-61.

32 Müller A, Leukefeld C, Hase C, Gruner-Labitzke K, Mall JW, Köhler H, et al. Food addiction and other addictive behaviours in bariatric surgery candidates. Eur Eat Disord Rev. 2018 Nov;26(6):585-96.

33 Scheffel O, Daskalakis M, Weiner RA. Two important criteria for reducing the risk of postoperative ulcers at the gastrojejunostomy site after gastric bypass: patient compliance and type of gastric bypass. Obes Facts. 2011;4(s1 Suppl 1):39-41.

34 Svane MS, Bojsen-Moller KN, Martinussen C, Dirksen C, Madsen JL, Reitelseder S, et al. Postprandial nutrient handling and gastrointestinal hormone secretion after Roux-en-Y gastric bypass vs sleeve gastrectomy. Gastroenterology. 2019;156(6):1627-41. e1.

35 Li G, Hou G, Yang D, Jian H, Wang W. Relationship between anxiety, depression, sex, obesity, and Internet addiction in Chinese adolescents: a short-term longitudinal study. Addict Behav. 2019 Mar;90:421-7.

36 Jeynes KD, Gibson EL. The importance of nutrition in aiding recovery from substance use disorders: a review. Drug Alcohol Depend. 2017 Oct;179:229-39. 